\title{
LA TARDÍA REORIENTACIÓN DE LA POLÍTICA ESPAÑOLA A FAVOR DE LOS ALIADOS
}

\author{
Antonio Marquina ${ }^{1}$ \\ Director de UNISCI
}

\section{Title in English: "The Late Reorientation of the Spanish Foreign Policy towards the Allies in World War II"}

Copyright $\odot$ UNISCI, 2014.
Las opiniones expresadas en estos artículos son propias de sus autores, y no reflejan necesariamente la opinión de UNISCI. The views expressed in these articles are those of the authors, and do not necessarily reflect the views of UNISCI.

\section{Introducción}

El fin de la segunda guerra mundial tuvo unos efectos perfectamente conocidos: la permanencia del régimen del general Franco en España. Esta permanencia se ha denostado o justificado desde diversas posiciones y ha dado lugar a toda una serie de escritos, ensayos y lucubraciones que se vieron en su día reforzadas por la publicación de algunos documentos diplomáticos del Departamento de Estado norteamericano. Se manejó durante mucho tiempo el término de política antiespañola de los aliados, pero no se buscaron las razones profundas o fácticas tanto de su apoyo a los grupos de la oposición republicana o monárquica como de la enemiga de los aliados contra el general Franco. Trataremos de elucidar en este artículo algunos de los aspectos más oscuros y/o más funestos que en su día influyeron en la tardía reorientación de la política española..Hay lecciones importantes que se pueden deducir para evitar cometer errores de notable envergadura.

\footnotetext{
${ }^{1}$ Antonio Marquina Barrio es Catedrático de Seguridad y Cooperación en las Relaciones Internacionales de la Universidad Complutense de Madrid, Director del Departamento de DIP y Relaciones Internacionales de la UCM, Director de UNISCI y Presidente del Foro Hispano-Argelino. Sus principales líneas de investigación son la seguridad en Europa, el Mediterráneo y Asia-Pacífico, y el control de armamentos.

Dirección: Departamento de Estudios Internacionales, Facultad de Ciencias Políticas y Sociología, UCM, Campus de Somosaguas, 28223 Madrid, España.

E-mail: marioant@cps.ucm.es.
} 


\section{El acuerdo secreto de mavo de 1944}

El gobierno del general Franco y los gobiernos de Estados Unidos e Inglaterra habían llegado a un acuerdo secreto el 2 de mayo de 1944, mediante un intercambio de notas por el que el gobierno español se comprometió a limitar las exportaciones de wolframio a Alemania, reduciéndose a veinte toneladas durante los meses de mayo y junio y elevándose un mes después a cuarenta toneladas, con las apropiadas deducciones por el mineral exportado de contrabando; la retirada de la misión militar japonesa y el cierre del consulado alemán en Tánger, con la marcha de todo su personal fuera de España; el sometimiento a arbitraje de la cuestión de los barcos de guerra italianos anclados en puertos españoles y la entrega de cinco de otros siete barcos mercantes italianos asimismo fondeados en puertos españoles tras la capitulación; la retirada final de cualesquiera unidades españolas del frente ruso; la continuación de todas las facilidades necesarias para la compra y exportación de productos españoles por parte de Gran Bretaña y Estados Unidos, y la expulsión de España de los agentes de espionaje y sabotaje alemanes. A cambio, Inglaterra y Estados Unidos se comprometían a reanudar el suministro de petróleo, cuyo corte intencionado había tenido como finalidad el poner fin al régimen del general Franco, pero la falta de liderazgo y cohesión en las alternativas de gobierno, así como fallos previos garrafales de los servicios especiales de Estados Unidos en España y norte de África, indujeron a los británicos a cancelar la operación conjunta preparada. Este acuerdo secreto habrá que tenerlo muy presente para la justa evaluación de algunos hechos que posteriormente expondremos. El gobierno del general Franco, la Falange, el Alto Estado Mayor y la policía española pensaban increíblemente que los aliados y sus servicios de inteligencia podían ser despistados con mayor o menor facilidad o con palabras altisonantes de neutralidad. El acuerdo secreto no fue cumplido en su totalidad. Este incumplimiento era consecuencia de otros pactos secretos realizados con anterioridad con la Alemania nazi, de los flujos de patriotismo que inducía el dinero alemán y en no menos medida de la satelización de muy influyentes sectores, para los que una derrota alemana e consideraba como la ruina de su situación política y del Nuevo Estado falangista surgido tras la guerra civil.

Veamos esto con algún detalle.

\section{El desastre de los servicios de inteligencia españoles}

Ya durante 1943 destacados ministros falangistas, como José Luis Arrese y José Antonio Girón, todavía habían propugnado en el Consejo de Ministros la entrada de España en guerra al lado de Alemania. Si bien esto no pudo ser conseguido, se hizo todo lo posible por parte de muy influyentes sectores falangistas y germanófilos que controlaban los aparatos del Nuevo Estado para seguir sirviendo lo mejor posible a Alemania. Todo ello sobre un sustrato hoy día documentalmente irrefutable: la complacencia del general Franco y su continua falta de apreciación de las realidades internacionales, que se puso de manifiesto en 1944 en hechos insólitos. El general Jordana, que había trabajado de forma consciente y entre dificultades sin cuento para una mejora de las relaciones con los aliados, era sustituido, tras su muerte, ocurrida el 3 de agosto, tras el desembarco en Normandía, por un germanófilo reconocido en el mundo internacional, José Félix Lequerica, embajador español ante la Francia de Vichy. Y en el mes de noviembre, el duque de Alba entregaba al secretario de Estado británico una carta del general Franco, fechada el 18 de octubre, en la que solicitaba una clarificación de las relaciones entre España e Inglaterra y ofrecía el apoyo español a Gran Bretaña en contra de Rusia. 
Es ilustrativo hacer un seguimiento de sus planteamientos en 1944. En los primeros meses de 1944 Franco no estaba convencido de la victoria de los aliados. A su juicio, la guerra sería larga y terminaría probablemente con una paz de compromiso. Así lo manifestaron al agregado militar británico tanto el general Martínez Campos como el general Kindelán. La razón no era otra que la influencia que ejercían el general Vigón y el germanófilo Alto Estado Mayor sobre el general Franco. Los informes españoles daban como imposible un éxito en la invasión aliada de Europa y que en cualquier caso Alemania permanecería fuerte en Europa, no previéndose su derrota. Además, no creía que los aliados estuviesen determinados a una rendición incondicional de Alemania y la destrucción de su Ejército, que, en su opinión, necesitarían contra la amenaza soviética. Luego vendría el desembarco en Normandía, y el general Franco mantuvo sus convicciones, pasados los meses de agosto y septiembre, cuando la derrota de Alemania parecía inminente. Los consejeros militares más cercanos, el general Muñoz Grandes y el general Vigón, le indicaron que Alemania todavía tenía posibilidades en la guerra y algunos acontecimientos, que se habían iniciado con la V-3 y otras armas secretas, podían hacer volver el viento a su favor. Para el general Franco, los consejos del Alto Estado Mayor y sus servicios de inteligencia, ligados con un acuerdo secreto al Estado Mayor alemán que perduraba, eran más importantes que las observaciones del Consejo de Ministros. Los británicos tenían, además, pruebas de que "muchos individuos del Alto Estado Mayor han estado recibiendo dinero alemán, que ha influenciado sus acciones y actitudes". 2

Este convencimiento de la dificultad de una derrota alemana, en opinión de la inteligencia militar británica, ya no existía en el mes de febrero de 1945, sin embargo, perduraron ciertas constantes. Unas semanas antes de la capitulación alemana, en conversación con el señor Matéu, ex alcalde de Barcelona, el general Franco se presentó como el paladín de la cristiandad contra las hordas ateas bolcheviques, el único jefe de Estado que no era masón y el último generalísimo de las fuerzas occidentales en una inevitable y final batalla contra la URSS, afirmando tener un conocimiento especial y secreto del conflicto que estaba avecinándose por un micrófono que estaba oculto en el despacho del general De Gaulle El duque de Alba, por su parte, salió también asombrado de sus entrevistas con el general Franco. En el mes de febrero le manifestó que las únicas naciones viriles que quedarían en Europa occidental serían Gran Bretaña y España, dada la situación de caos de Francia e Italia; Gran Bretaña, aseguró, necesitaría el apoyo de España contra Rusia. En el mes de abril, Franco llegó a afirmar que no estaba convencido del colapso de Alemania, ya que cuando los ejércitos británico-norteamericanos se encontrasen en Alemania con el ejército soviético comenzarían a luchar uno contra otro ${ }^{3}$.

Empero, algunos cambios tardíos se fueron introduciendo, pues el general Franco nunca jugaba a una sola carta, si bien con una importante característica, cambios que en su opinión no sirviesen para debilitar la estructura del Nuevo Estado que inevitablemente habría de unirse con Gran Bretaña y Estados Unidos en su lucha contra la Unión Soviética.

A finales de septiembre de 1944 fueron enviadas a la prensa unas directivas procedentes de El Pardo, a través del jefe del departamento de prensa y propaganda de la Falange, Juan Aparicio, sin previa consulta con José Luis Arrese, ministro secretario del partido. En ellas se instruía a la prensa para que evitase cualquier orientación germanófila en los comentarios

\footnotetext{
${ }^{2}$ Para el acuerdo secreto con los aliados, véase FRUS 1944 V.IV, pp.410 y ss., N. A., OSS 66125; F. O. 371, 49589/Z9333; FO. 371, 39677/C12749; para las opiniones del general Franco y la actitud del Alto Estado Mayor, a falta de documentación española, véase FO. 371, 39716/C1400; FO. 371, 39736/Z2742; N. A. 0SS/L51691; el juicio británico en FO. 371, 49587/Z1593.

${ }^{3}$ FO. 371, 49629, 78; 49611 /Z2972/Z3253; 49610/Z2099
} 
políticos y diese preferencia a los comentarios de guerra aliados, cesando toda crítica sobre Rusia; si bien la Falange emprendió una violenta campaña de propaganda distribuyendo panfletos que advertían del peligro comunista y del supuesto eco que la oposición española en el exilio («los comunistas») encontraba en la Cámara de los Comunes británica. La Falange de hecho sufrió muy pocos cambios. Al mismo tiempo que se ofrecía a Raimundo Fernández Cuesta el puesto de ministro secretario del partido en lugar de José Luis Arrese, con el fin de convertir la Falange en una organización menos significada políticamente, se nombraban en el mes de noviembre nueve gobernadores civiles tan fervientes falangistas como sus antecesores.

La burocracia falangista resistió el envite. En este momento, se calculaba que incluía a 20.000 personas, es decir, 20.000 personas que recibían salarios regulares del partido. De éstos, cerca del millar eran agentes fijos del servicio de inteligencia falangista, sin incluir los miembros falangistas del cuerpo de Policía y los informadores de todo tipo que apoyaban al partido. Sobre esta estructura y los acuerdos de 1940, la Gestapo había conseguido controlar la policía española con el apoyo asimismo de los elementos germanófilos del Alto Estado Mayor, ya que los más importantes puestos de la dirección general de Seguridad estaban asignados a mandos militares. A fines de 1944, la dirección general de Seguridad seguía cooperando y apoyando los intereses alemanes, permitiéndoles seguir escuchando las conversaciones telefónicas de cualquier ciudadano u organismo oficial, la apertura de cartas y telegramas e incluso el interrogatorio de los detenidos.

A su vez, la milicia falangista estaba considerada en este momento como una fuerza de reserva que podía ser llamada, en una situación de emergencia, a reforzar la policía regular en caso de desórdenes, huelgas, etcétera. Una especie de somatén de reserva. A esto hay que añadir otra serie de medidas, como la formación, en agosto de 1944, de un cuerpo de élite, la Guardia de Franco, con miembros de la Vieja Guardia y de la División Azul; la venta a bajo precio y distribución de armas cortas, de una forma no oficial e indiscriminada, a diversos sectores falangistas; o la formación de listas negras. Es interesante a este respecto constatar las directrices de una orden emanada de la secretaría general del partido, el 21 de septiembre de 1944, a todos los jefes de distrito de Madrid. Eran las siguientes: lista de rojos que han estado activos en el pasado o durante la guerra civil, con todos los posibles detalles referentes a sus actividades y su situación presente (libertad, libertad provisional, libertad restringida, prisión); indeseables, es decir, aquellos que, estando sin una afiliación definida, podrían sacar partido de cualquier agitación o desorden para sus propios propósitos; extranjeros que han residido en España desde la guerra civil; simpatizantes rojos, es decir, aquellos que no han tomado parte en actividades rojas, pero, sin embargo, simpatizan con ellos y hacen todo lo posible para hundir el Movimiento, propagando rumores y falsas historias.

Estas directrices fueron pasadas a los "jefes de casa" que la Falange había establecido en cada edificio de viviendas y cuya función consistía en espiar e informar de la actividad de todos los residentes, forzando a los porteros a cooperar, informando de las visitas bajo pena de expulsión del puesto de trabajo o represalias.

\section{El incremento de detenciones $\mathrm{v}$ eiecuciones}

Simultáneamente se incrementaron, en la segunda mitad de 1944, las detenciones políticas y las ejecuciones de prisioneros. Unos, detenidos por actos clandestinos considerados hostiles al régimen, y otros, que todavía esperaban el cumplimiento de la sentencia desde el final de la guerra civil. El gobierno británico tuvo incluso que intervenir ante la secretaría de Estado del Vaticano presentando un informe detallado del número de ejecuciones, condenas a muerte y 
detenciones de un régimen que se presentaba como paladín de la cristiandad, que no pudieron menos de causar estupor y fueron enviados al nuncio Cicognani para información y encuesta. Estas medidas trataban de poner freno al impacto de las victorias aliadas sobre la opinión pública, cuando numerosos falangistas habían empezado a ocultar sus uniformes y la oposición al régimen empezaba a inquietarse y organizarse.

Sin embargo, la presión aliada y la influencia del ministerio de Asuntos Exteriores pesaron algo. El general Franco, en unas declaraciones al representante de la United Press, en el mes de noviembre, que fueron acogidas con enorme reticencia por los extremistas de la Falange, aunque ponía de manifiesto su escaso interés por un cambio profundo en la situación política, describía los pasos dados en la construcción de una democracia orgánica, primero, con la constitución de las Cortes, luego, con unas típicas elecciones sindicales y la promesa de una nueva ley de Administración Local que regulase las elecciones municipales. Poco después apareció en el Boletín Oficial del Estado una ley orgánica por la que se resucitaba el Consejo de Estado, y al final de año llegaron noticias a la Embajada británica de que el general Franco «seguía con- templando» la supresión del puesto de ministro secretario general del partido, junto con el paso de la sección de prensa y propaganda al ministerio de Gobernación y la incorporación de la milicia falangista al Ejército ${ }^{4}$.

\section{La Junta Suprema de Unión Nacional y la invasión del valle de Arán}

Hay que añadir a todo este entramado un hecho de suma importancia: la invasión de los maquis en el valle de Arán, en el mes de octubre de 1944. Esta operación ha-sido más o menos encomiada y puesta en el activo de la Unión Nacional Española. La tesis tradicional asegura que la delegación del comité central del PCE dentro de España envió una directiva a la delegación en Francia en el momento de la liberación para crear un frente militar en el lado español de los Pirineos, y que esta delegación y el mando de las fuerzas guerrilleras organizaron la ocupación del valle de Arán simultáneamente con otras operaciones secundarias siendo un completo fracaso. Este acontecimiento, que en la primera semana no recibió ninguna cobertura informativa, sí la recibió a partir del 11 de octubre por la prensa y la radio españolas (días 11, 17, 19, 22, 24, 25 y 26 de octubre).

George Hills ha llegado a asegurar que en la historia moderna no existe ninguna otra ocasión en la que 1.500 guerrilleros bien armados hayan sido tan fácilmente derrotados. Posiblemente existan causas mucho más profundas que se pueden esbozar en este artículo. Es muy posible que en esta acción guerrillera no se pueda descartar la mano de Alemania. Dejando de lado las manipulaciones de la Gestapo y el Intelligence Service en el sur de Francia, hay desclasificados varios informes, tanto británicos como norteamericanos, que llaman poderosamente la atención.

El más significativo y más resaltado en su día por el Foreign Office, al ser mandado imprimir, pertenece al cónsul británico en Barcelona, Harold Farquhar. Este consulado, uno de los centros fundamentales del espionaje británico en España, con amplias ramificaciones en el sur de Francia, envió una misión. informativa compuesta por los vicecónsules Dorchy y Amoore a Toulouse, otro centro importante de la inteligencia británica durante los años cuarenta.

A su vuelta prepararon un amplio informe top secret del que Harold Farquhar resaltaba, entre otros aspectos, los siguientes: "La UNE podía muy bien compararse con la EAM de Grecia. Se especula mucho sobre la procedencia de los fondos que les sirven de base. En

\footnotetext{
${ }^{4}$ FO. 371, 39688/C17111; NA. OSS/L50235; FO. 371, 39678/C15615/C16067.
} 
ausencia de una prueba definitiva en contrario, puede muy bien tratarse de los alemanes, que están interesados en fomentar la anarquía y el desorden en todos los países liberados por los aliados. Existe una notable evidencia en el sentido de que muchos de estos extremistas republicanos trabajaron para la Gestapo durante los años de la ocupación alemana de Francia”. De la misma opinión era la información llegada al Departamento de Estado con fecha de 27 de septiembre, desde Figueras, antes de iniciarse la operación.

Existen asimismo informes hoy día accesibles de los servicios de inteligencia aliados, en especial de la inteligencia militar británica, desde los primeros meses de 1943, sobre preparativos alemanes de todo tipo para el caso de una posible derrota, pero esto nos llevaría demasiado lejos. Digamos únicamente que estos elementos exaltados contribuyeron a cohesionar al Ejército en torno a Franco en un momento delicado de posible transición ${ }^{5}$.

\section{La posibilidad de golpe de Estado}

La situación del Ejército antes de esta operación del valle de Arán era apreciada de la siguiente forma por los servicios de inteligencia aliados:

El apoyo de los generales más antiguos era esencial para el éxito de cualquier levantamiento. La mayoría de los generales enérgicos y de carácter habían sido colocados en lugares menos relevantes, caso de Kindelán, o, incluso sometidos a estricta vigilancia, caso de Aranda. Ninguna acción era posible por parte de generales más pusilánimes sin el apoyo de aquellos generales. La junta militar, financiada por el Reino Unido, no se había distinguido por la reserva de sus componentes y a finales de 1943 había dejado ya de tener interés para los aliados.

Entre los mandos inferiores al cargo de coronel existía una gran diferencia de opinión. La mayoría probablemente era leal a Franco, a quien debían su posición y muchos privilegios, pero existía un amplio sector de descontentos. Estos últimos estaban constituidos principalmente por militares de carrera que estaban muy molestos por la política de nombramientos que se había llevado a cabo, dando preferencia a individuos en función de los especiales servicios prestados al partido o durante la guerra civil. Todos aquellos que habían sido pasados a la reserva o que habían sido sobrepasados en las promociones había que contar entre los descontentos.

En aquel momento, se opinaba que estos elementos descontentos estaban a medio camino entre los extremos, constituidos por los oficiales pro Franco y los oficiales ex regulares retirados del Ejército por actividades republicanas antes o durante la guerra civil. Existían indicios de que tales elementos, en caso de un inicio de disturbios, podrían ver la oportunidad de unir sus fuerzas con los oficiales republicanos retirados en una revuelta contra el régimen.

Las escalas inferiores se encontraban en una situación lamentable y la tropa, en su mayoría, simpatizaría con la izquierda, si bien el sentimiento variaba de acuerdo a los diferentes regimientos. Algunos dispararían contra el pueblo si se les ordenase hacerlo, y otros no. En los casos en que los oficiales estuviesen a favor de la oposición, sus hombres probablemente les seguirían.

En conclusión, se afirmaba lo siguiente: “Aunque existe un amplio núcleo de personas insatisfechas dentro del Ejército e incluso la policía, todo depende del liderazgo de uno o más generales enérgicos. Si tuviese éxito una revuelta preliminar, se le podría unir inmediatamente

\footnotetext{
${ }^{5}$ FO, 371, 39735/C15431; 49553/Z161; N. A. OSS/112771.
} 
un bloque compacto con suficiente fortaleza para asegurar un éxíto final. La ventaja de Franco consiste en que es muy difícil para cualquier general montar la organización necesaria para llevar a efecto un ataque al régimen sin recibir antes detalles de los preparativos. Por esta razón, una victoria democrática en Europa es tan ansiosamente esperada por la oposición y se piensa que reforzará la determinación de los generales vacilantes y debilitará la posición de Franco y la Falange" 6.

Pero el general Franco, que recibió a su vez diversos informes con indicaciones acerca de la dudosa lealtad del Ejército, procedió a ordenar un endurecimiento de las medidas de control de los mandos y la tropa, a la vez que ordenaba una distribución en diversas unidades de oficiales de las milicias falangistas del SEU, perfectamente seleccionados por sus ideas políticas, su fanatismo al servicio de la Falange y los sentimientos de sus familiares. Asimismo, manteniendo concentrado el Ejército en las provincias del norte de España por el peligro revolucionario, se evitaba el peligro de dispersión, que fue tan negativo para la II República.

El refuerzo que supuso la invasión del valle de Arán para la unidad del Ejército, así como estas medidas, tuvieron su efecto. El agregado militar británico informaba, a finales de enero de 1945, que "los generales están todavía en el estadio de maniobrar para alcanzar posiciones. Ningún grupo, sin embargo, tiene las suficientes como para que le permitan llevar a cabo un golpe de Estado por sí solos”. El general Kindelán se encontraba totalmente desilusionado y pensando que los días propicios para llevar a cabo una acción ya habían pasado.

En el mes de marzo de 1945 tuvieron lugar unas reuniones en el Consejo Superior del Ejército, de las que existen narraciones no del todo exactas y en las que intervino el general Franco. El general procedió a explicar a los otros generales que nunca la situación había sido más tranquila. La Falange era un elemento de estabilidad y después de la guerra los países extranjeros, de modo especial Estados Unidos, imitarían y adoptarían los principios de la Falange. El general Franco afirmó que mantenía buenas relaciones con De Gaulle, y que Gran Bretaña estaba terminada, aunque admiraba a su primer ministro, a quien tenía en gran estima, que le había confesado que estaba en manos de los masones. Rusia se encontraría exhausta al final de la guerra y se retiraría a sus fronteras, por lo que, a su juicio el peligro, comunista no vendría de Rusia, sino de Francia y Gran Bretaña, donde la masonería daría paso al comunismo. El único país que contaría después de la guerra sería Estados Unidos, con el que estaba en las mejores relaciones.

Ante estas alucinantes declaraciones, sólo hizo observaciones el general Kindelán, manifestando que después de lo allí escuchado estaba más preocupado que antes y que mientras permaneciese la Falange serían imposibles buenas relaciones con Francia y Gran Bretaña. Era pura ilusión contar con el apoyo de Estados Unidos. Estas observaciones fueron acogidas con la irrisión compasiva del general Franco y se levantó la sesión con un mutis general $^{7}$.

A su vez, los aliados, que siguieron muy de cerca todos los acontecimientos españoles, no esperaron al final de la guerra para establecer su criterio y la política a seguir con el régimen del general Franco. Se ha aireado mucho la posición de Churchill en Potsdam. Esta posición estaba ya tomada mucho antes, en el otoño de 1944.

\footnotetext{
${ }^{6} \mathrm{NA}, \mathrm{OSS} / \mathrm{L} 50388$.

${ }^{7}$ NA, OSS/L48387; D S D F 852.00/2-2645; FO 371, 49587/Z1595/Z4137.
} 
En los meses de octubre-noviembre de 1944, el Foreign Office consideró que Gran Bretaña necesitaba relaciones estrechas y amistosas con España por razones estratégicas y una España próspera y amistosa con la que desarrollar su comercio. Estos eran dos aspectos fundamentales. Sin embargo, no existían perspectivas de unas relaciones satisfactorias en tanto permaneciese inalterado el régimen del general Franco, que se consideraba un anacronismo si la guerra finalizaba. Habida cuenta que un cambio violento de régimen por medio de una revolución no era aconsejable para sus intereses, al implicar probablemente la ascensión de elementos extremistas, y dado que la vasta mayoría del pueblo español se oponía a una nueva revolución, era necesario pensar en algunas alternativas.

No era oportuna la continuidad del régimen, pues antes o después se produciría una revolución, y lo deseable, un régimen moderado monárquico o republicano, ya era casi un pío deseo (sic) en función de la situación de depresión y apatía, en que se encontraban los elementos moderados. El diagnóstico era claro, los únicos que podían echar a Franco eran los generales. Por tanto, Inglaterra -se concluía- a lo más que podía aspirar era a una modificación del régimen y a la su presión de sus aspectos más intolerables. En este sentido se acordó el envío de una seria advertencia al gobierno español, al descartarse una injerencia decidida en la política interior española.

La advertencia tuvo lugar tras la contraofensiva aliada en Las Ardenas finalizada el 25 de enero de 1945. El primer ministro procedió a contestar la carta del general Franco de 18 de octubre. Esta carta, redactada por Anthony Eden y aprobada por el Gabinete, así como una copia de la misma para Stalin, estuvo retenida tres semanas en el Foreign Office. El Foreign Office era favorable a hacer una presión conjunta con el Departamento de Estado ante el gobierno español, pues dado el comportamiento de la embajada americana en Madrid, el general Franco estaba en la idea de que iba a contar con el beneplácito de Estados Unidos. Pero Churchill fue de opinión contraria.

$\mathrm{Su}$ experiencia en el trato con los norteamericanos durante la guerra ("los americanos son muy anti-Franco e incluso anti-españoles") le llevó a ordenar el mero comunicado de la carta al presidente Roosevelt, pero sin urgir una coalición ("no tengo la menor intención de iniciar una cruzada anti-Franco, de la misma manera que no deseo pasear por la calle con él cogido del brazo"). Lo mismo hizo con Stalin, esperando ablandarle y disuadirle de cualquier intervención. En la carta negaba imperturbablemente las acusaciones de Franco sobre las actividades de los agentes británicos en España y se recordaban las actuaciones españolas durante la guerra y la actitud del partido falangista, claramente enemistosa, reconocido oficialmente como el fundamento de la estructura del Estado. En esas circunstancias, no había razón para esperar un apoyo del gobierno británico a la petición española de participar en un eventual acuerdo de paz ni una invitación para la admisión de España en la futura organización mundial. En cuanto al peligro soviético, la posición de Churchill era meridiana: la colaboración anglo-rusa basada en el tratado de 1942 se consideraba esencial dentro del marco de la futura organización mundial.

El general Franco indicó posteriormente al duque de Alba que las apreciaciones de Churchill eran las de un hombre esclavo de la masonería, siendo la cabeza de un país decadente y corrompido que, como él, estaba bajo el control de la masonería internacional; las relaciones exteriores de España, aseguró, se basarían en un futuro en América, pudiendo ignorar por completo a Inglaterra.

Pero al poco tiempo recibió una carta del presidente Roosevelt despertándole de sus ensueños y en la misma línea que la carta de Churchill, si bien mucho más dura en su 
redacción, recordando no sólo las actividades, anti-aliadas de la Falange, sino que no había sitio en la comunidad internacional para gobiernos fascistas ${ }^{8}$.

Mientras tanto, estaban teniendo lugar en España una serie de acontecimientos asombrosos que nos pueden dar una idea de la profundidad de las relaciones y lazos, existentes anteriormente con la Alemania nazi.

\section{Perduran las facilidades a Alemania}

Ya indicamos que durante 1944 existió una fuerte pugna diplomática entre las embajadas norteamericana y británica con el Ministerio de Asuntos Exteriores español para el cumplimiento del acuerdo secreto del mes de mayo. El tema de los agentes alemanes y el wolframio, de modo peculiar, fueron puntos de especial fricción.

Con el nuevo año 1945, la embajada de Gran Bretaña procedió a recordar al gobierno español la situación de incumplimiento del acuerdo, en particular la obligación asumida de prevenir las actividades de los agentes alemanes, incluyendo una lista de 83 agentes que todavía permanecían actuando en España y de otros cuatro que permanecían en el norte de África; la situación de los agentes internados en el campo de Caldas de Malavella, que podían recibir y hacer llamadas telefónicas a larga distancia, disfrutando de completa libertad de recibir visitas y de movimiento, casi como si se tratase de un centro situado cerca de la frontera de Francia para proseguir sus actividades; la desaparición de quinientas tm. de wolframio de las plantas de almacenaje de Sofindus, a pesar de las seguridades recibidas; la continuación del servicio de la compañía Lufthansa, que permitía la entrada y salida de agentes alemanes, y el envío de mercancías bajo la apariencia de paquetes postales, de gran importancia para el esfuerzo guerrero alemán, así como los viajes de personal y técnicos especializados y la traída de planos y patentes de alto interés militar; la no solución del problema de las libras falsificadas por Alemania, introducidas en España por valija diplomática y cambiadas por agentes alemanes y españoles que permanecían en libertad; la ocultación de activos alemanes por testaferros y abogados españoles con muy pingües beneficios, a los que nadie en su sano juicio podría calificar como personas independientes o de la resistencia, y otra serie de actividades claramente favorecedoras del esfuerzo guerrero alemán. De entre estas últimas son de destacar, por su espectacularidad, algunos ejemplos:

En el mes de febrero de 1945, el agregado naval de Estados Unidos en Tánger, tras repetidas protestas caídas en el vacío, lograba hacerse acompañar por un oficial español para inspeccionar una casa de la calle del Teniente Pacheco, de la que vieron saltar a un hombre por la ventada al advertir su presencia, y en la que encontraron un radio transmisor, códigos y mensajes para la transmisión de los movimientos de los barcos aliados en la zona del Estrecho a los submarinos alemanes que todavía operaban.

Más clamoroso fue el caso de los suministros por barcos españoles de pequeño tonelaje a los focos de resistencia alemana en Francia. Los servicios navales británicos y norteamericanos, con el apoyo de los servicios vascos, detectaron este tráfico en el verano de 1944, y las protestas se sucedieron. Los barcos detectados, doce en total, dos de ellos comprados y no utilizados, estuvieron haciendo viajes a la costa francesa hasta iniciado el mes de abril del 1945 en algún caso, llevando alimentos, medicinas, cigarrillos, botas, etcétera.

La respuesta española a los detalles y alegaciones británicas del 25 de abril de 1945 no fue muy convincentes.

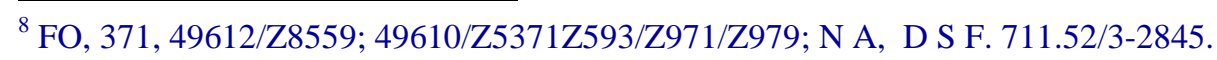




\section{EE UU v el Reino Unido prefirieron en 1945 la evolución del régimen que forzar su caída}

Con la estrepitosa derrota del III Reich, en mayo de 1945, los alemanes no acabaron sus actividades en España. En junio de 1945, el agregado militar británico informaba que estaba muy impresionado de la visita que había hecho a las dependencias de la antigua embajada alemana y del tamaño de la organización y el staff del agregado militar alemán, añadiendo: "Hemos estado averiguando el paradero y actividades del personal de los servicios alemanes, diplomáticos, agentes, etcétera, y haciendo las necesarias gestiones ante el gobierno español para contrarrestar sus actividades y prevenir el establecimiento de una organización que pueda trabajar desde aquí en el futuro".

"Estimamos", continuaba el informe del agregado británico, "que hay cerca de 20.000 alemanes, en España, y muchos están todavía libres y en actividad. La mayoría tienen dinero y propiedades. Han sido ayudados y cubiertos por la Falange y, en alguna medida, por el Alto Estado Mayor, que todavía mantiene sentimientos pro-alemanes y está en estrecho contacto con los alemanes en este país. Los alemanes han estado preparándose desde hace bastante tiempo para el día de nuestra victoria. Los miembros de la Gestapo recibieron pasaportes especiales de la policía española, que son válidos hasta el 31 de marzo de 1946, al mismo tiempo que parece que el director general de Seguridad les informó que, en caso de que fuesen a ser detenidos o enviados fuera del país, les avisarla con bastante antelación. Se les han entregado fondos monetarios provenientes del partido nazi alemán o Auxilio Social, de este modo los alemanes pueden contar con la amistad no sólo del partido falangista, sino de la mayoría de los miembros del gobierno actual, ex miembros de la División Azul y un número considerable de españoles que son pro-alemanes".

A continuación añadía "En estas circunstancias es extremadamente difícil hacer algo que afecte a los alemanes o sus intereses, y estoy de acuerdo con nuestro encargado de negocios: que la figura siniestra de la Falange no se basa tanto en sus ideas de corte nacionalsocialista cuanto en los asuntos para los que han sido utilizados bajo control alemán, como la Gestapo, servicios secretos, etcétera. Mientras el régimen presente continúe con sus elementos germanófilos -no sólo la Falange, sino el Alto Estado Mayor-, existe el peligro de que los alemanes continúen sus actividades en España. Por esta razón, posiblemente es de mayor importancia inmediata para nosotros erradicar los alemanes de España que obtener la disolución de la Falange"9. La pregunta que inmediatamente puede surgir, después de esta exposición, es ¿por qué el Reino Unido, de modo especial, y Estados Unidos consideraron menos peligrosa esta situación?

Ya indicamos anteriormente las apreciaciones británicas. Dado que primaban los intereses estratégicos y económicos, hubiese sido necesaria una oposición política al régimen de Franco más unida y coherente, teniendo además en cuenta la fuerte ofensiva policial y parapolicial que estaba teniendo lugar. A esto se respondió desde algún sector de la oposición, en los primeros meses de 1945, con la colocación de algunos artefactos y el asesinato de varios falangistas, sobre lo que se montó una gran operación propagandística y de represión. Muchos falangistas que habían ocultado sus camisas las desempolvaron y mucha gente vio reforzada su creencia de que la Falange era menos peligrosa que el comunismo, al ser comunistas los asesinos de los falangistas madrileños, reviviéndose la posibilidad de los horrores de otra guerra civil, que para la propaganda oficial había sido una lucha contra el comunismo. Luego vendría el manifiesto de don Juan, que tuvo poca resonancia e influencia en los grupos monárquicos, quienes, en gran número, lo juzgaron como hecho a destiempo.

\footnotetext{
${ }^{9}$ FO, 371, 496 10/Z593, y todos los documentos de los legajos FO, 371, 49548,49549,49550; NA, ABC. 393 , 4 Germany (11- 1- 1944), ABC. Tánger (13-2-1945).
} 
En el mes de julio de 1945 la evaluación de la situación por el Foreign Office no había cambiado. Los monárquicos seguían tan ineficaces como siempre, los generales hablaban mucho y hacían poco y el general Franco, que había colocado a sus fieles en los puestos clave, era más fuerte que nunca.

Por su parte, la embajada norteamericana, que cultivó más estrechamente a los elementos republicanos, de forma especial al partido comunista a través de la OSS, hacía en el mes de octubre un informe-resumen de los informes políticos de los consulados de Barcelona, Bilbao, Málaga, San Sebastián, Sevilla, Valencia y Vigo. Consideraba que los grupos republicanos y socialistas se habían ido fortaleciendo, mientras se habían ido volviendo más confusos y divididos los monárquicos. La represión continuaba y no existían indicios de acuerdo entre monárquicos y republicanos, ni existían líderes, apoyos económicos serios, programas definidos, ni organizaciones capaces de amenazar el régimen o asumir responsabilidades de gobierno. La oposición había esperado que Londres y Washington les echase una mano, obviando en su opinión la necesidad de trabajar duramente en sus propias organizaciones políticas. La República restablecida en el exilio no se consideraba representativa por los republicanos del interior. El informe finalizaba asegurando que "únicamente en los meses más recientes, el régimen había admitido que debía evolucionar y reformarse; además, ahora, por primera vez, se pone en cuestión si Franco es más un activo político que un pasivo, siendo abiertamente discutida la cuestión entre sus fervientes seguidores. Obviamente, la levadura está actuando en la masa, pero no existe una inmediata, simple y satisfactoria solución del problema político interno español"10.

En esta situación, se produjo la entrada en el ministerio de Asuntos Exteriores de Alberto Martín Artajo, presidente de la Junta de Acción Católica, la más importante maquinaria no falangista, intentando llevar a cabo una reforma del régimen desde dentro, que a los pocos meses se consideró por no pocos dirigentes de Acción Católica como un grave error, al haber servido únicamente de nueva pantalla exterior para el régimen. A lo que vino a añadirse una poco cauta identificación de la mayoría del clero católico, salvo excepciones, con el régimen de Franco, en especial el bajo clero, que aceptaba sin más aditamentos la línea anticomunista de la Falange; la eficacia del aparato falangista y policial; la inefectividad de las junta militar, completamente desgastada; el apoyo de los monárquicos colaboracionistas; y una postura británica y también norteamericana, tras la muerte de Roosevelt, favorecedora de la evolución y no del ahogo del régimen.

De este modo, el fin de la segunda guerra mundial supuso para el general Franco una pasajera pesadilla. España había llegado a ser un país del Eje, tras su adhesión al Pacto de Acero, pero este aspecto crucial de la política española interesadamente se ocultó, por más que se aislara y condenara al régimen de Franco, condena y aislamiento que impactó muy negativamente en el desarrollo y bienestar de los españoles durante muchos años.

\footnotetext{
${ }^{10}$ FO, 371,49587,49612/Z8559; N A. 13.S.D.F. 852.00110845.
} 